\title{
Introducing urine-enriched biochar-based fertilizer for vegetable production: acceptability and results from rural Bangladesh
}

\author{
Ipsita Sutradhar ${ }^{1}$ (D) - Meredith Jackson-deGraffenried ${ }^{2}$ (D) Sayema Akter $^{1}$ (D) \\ Shannon A. McMahon ${ }^{3,4}$ (D) . Jillian L. Waid ${ }^{2,3,7}$ (D) Hans-Peter Schmidt ${ }^{5}$ (D) \\ Amanda S. Wendt ${ }^{3,7}$ (D) Sabine Gabrysch ${ }^{3,6,7,8}$ (D)
}

Received: 15 January 2019 / Accepted: 24 December 2020 / Published online: 19 February 2021

(C) The Author(s) 2021

\begin{abstract}
Improved agricultural practices that increase yields and preserve soils are critical to addressing food insecurity and undernutrition among smallholder farmer families. Urineenriched biochar has been shown to be an accessible and effective fertilization option in various subtropical countries; however, it is new to Bangladesh. To better understand attitudes and experiences preparing and using urine-enriched biochar fertilizer, mixed-methods research was undertaken among smallholder farmers in northeastern Bangladesh in 2016/2017. In-depth interviews were conducted with 25 respondents who had compared the production of crops grown with biochar-based fertilizer to usual practice. In addition, in areas where trainings on biochar-based fertilization had been offered, 845 farmers were asked about their experience through a quantitative survey. Interview results indicated that cow urine-enriched biochar was favored over human urine because cow urine was perceived as clean and socially acceptable, whereas human urine was considered impure and disgusting. Respondents praised biochar-based fertilizer because it increased yields, cost little, was convenient to prepare with readily available natural materials, produced tastier crops, and allowed families to share their larger yields which in turn enhanced social and financial capital. Comparative field trials indicated a $60 \%$ yield benefit in both cabbage and kohlrabi crops. Challenges included uneven access to ingredients, with some respondents having difficulty procuring cow urine and biomass feedstock. The low social, health, and financial risk of adoption and the perceived benefits motivated farmers to produce and apply biochar-based fertilizer in their gardens, demonstrating strong potential for scale-up of this technology in Bangladesh.
\end{abstract}

Keywords Agricultural production · Family farms $\cdot$ Home gardening $\cdot$ Biochar $\cdot$ Urine $\cdot$ Bangladesh

Sabine Gabrysch

sabine.gabrysch@pik-potsdam.de

Extended author information available on the last page of the article 


\section{Introduction}

A growing global population, compounded by higher incomes, has led to an increasing demand for food production (Elferink and Schierhorn 2016). With decreasing availability of arable land, the challenge will be to increase production on existing agricultural lands, in part by adoption of new and innovative methods that improve soil fertility and water management (Elferink and Schierhorn 2016; Molden et al. 2007; FAO 2014). Nearly $90 \%$ of the 525 million farms worldwide are small scale (defined as $<2$ hectares) (IAASTD 2009) and often run by families. These family farms produce more than half of the world's total food (Graeub et al. 2016). Leveraging food production in small farms through improved production practices is therefore increasingly seen as a solution to global food insecurity and rural poverty (Graeub et al. 2016; FAO 2014).

In Bangladesh, the agriculture sector was a main contributor to poverty reduction from 2005 to 2010 (World Bank 2013), but smallholder family farms still experience low productivity (FAO 2016), leading to poverty and food insecurity among smallholder farming households (Bélières et al. 2015). Seventy-seven percent (77\%) of smallholder farmers in Bangladesh live below the poverty line (Hernandez et al. 2017), and while the country is self-sufficient for rice, it produces only a quarter of the fruits and vegetables needed to meet an adequate diet (Siegel et al. 2014). Homestead gardening can be an efficient and sustainable solution, but land is limited in densely populated Bangladesh (Ali 2005).

To increase productivity on limited agricultural land requires farmers to devise strategies for improving soil fertility and water management (Molden et al. 2007; FAO 2014). Industry-produced fertilizers can be prohibitively expensive for small-scale farmers and hamper soil fertility in the long term (Diacono and Montemurro 2011). In contrast, organic fertilizers improve soil microbiology and fertility in the short and long term (Steiner et al. 2007). In addition, they can be made with locally available materials at low cost and are therefore considered a sustainable and locally appropriate solution to the problem (Schmidt et al. 2017).

Biochar is produced by heating biomass (such as wood, nut shells, leaves or rice straw) to temperatures above $400{ }^{\circ} \mathrm{C}$ in an oxygen-limited environment (Kookana et al. 2011). Due to its highly porous and absorptive structure, biochar can retain and administer nutrients to the soil, including under conditions of water inundation. Combined with organic nutrients, such as compost or urine, biochar holds potential as a low-cost solution to depleted soil fertility and as a means to bolster agricultural production, especially in tropical and subtropical climates (Atkinson et al. 2010; Jeffery et al. 2017).

Urine, from both animals and humans, is an easily accessible, little-to-no-cost organic product containing high levels of nutrients needed for plant growth (Jönsson et al. 2004). While animal waste (including urine and manure) is routinely recycled into crop fields in larger, mechanized farms, it is not widely used at smallholder farmer levels. Reasons for this include the lack of technical equipment, the unpleasant odor of urine, and social norms that inhibit its handling (Mariwah and Drangert 2011). When combined with biochar, urine can be transformed into an odorless, solid, and nutrientrich organic fertilizer.

Recent trials of improved practice have shown that urine-enriched biochar fertilizer can be highly successful (Schmidt et al. 2017). In Nepal, for example, the production of over 20 vegetable, fruit, and cereal crops doubled on average with the use of urineenriched biochar fertilizer compared to the traditional organic fertilizing practice, and 
the biochar-based fertilizer was at least equal to the efficiency of mineral fertilizer (Schmidt et al. 2017). In Bangladesh, we are not aware of any previous studies on the practicality of using biochar-based fertilizer or how it is perceived by farmers.

The process of technology adoption has classically been conceptualized through the theory of "Diffusion of Innovation" (Rogers 2003), though many have highlighted limitations in its oversimplification of the adoption process, such as assuming a linear trajectory of adoption (from non-adopter to adopter) and a consistent technology (that does not change due to local adaptations or over time) (Feder et al. 1985; Glover et al. 2017; Temple et al. 2016). The importance of participatory designs has also been highlighted as part of the development and adaptation of new technologies (Cerf et al. 2012; Klerkx et al. 2012), with the notion of scaling as a continuous process in which technology and technology practices are adapted to local contexts and priorities (Wigboldus et al. 2016). These more nuanced interpretations of technology adoption and adaptation have recently been conceptualized as a new framework using the theory of affordances (Gibson 1979) which describes the process in four steps: proposition, encounter, disposition, and response (Glover et al. 2019). This framework could be helpful to explore the preparation and use of urine-enriched biochar in rural Bangladesh and how adaptations to the technology or practices could encourage sustained adoption.

Women play a crucial role in the agricultural sector, particularly in low-income countries in Asia and Africa (Lal and Khurana 2011; Ogunlela and Mukhtar 2009), and their increased participation has the potential to increase agricultural production (Quisumbing et al. 2014). However, women's contributions to agricultural development are undervalued and they are often excluded from decision-making processes (Ogunlela and Mukhtar 2009). In agriculture technology adoption, the consideration of gender has often been simplified to comparing adoption rates of male- to female-headed households or plot managers, and more recently, joint decision-making households (Doss 2015; Gebre et al. 2019). However, beyond technology adoption, women and men may perceive different benefits of a technology or face different barriers to uptake and use over time. In rural Bangladesh, women often abide by traditional gender norms which include restricted mobility outside of the homestead-due to purdah, imperatives to maintain respectable reputations, and perceived safety risks-as well as low asset ownership and limited decision-making ability (Rubin et al. 2018; Naved et al. 2011). Considering the context of these traditional gender roles and expectations is crucial when exploring the involvement and perceptions of women farmers in the adoption of agricultural innovations such as biochar-based fertilizer.

Our study aim was to examine acceptability of urine-enriched biochar fertilizer use among smallholder family farmers in Bangladesh using a mixed-method approach combining qualitative, survey, and experimental field trial data. We also aim to highlight potential drivers of behavior change to adopt the practice of preparing and utilizing urine-enriched biochar, which may inform future interventions in Bangladesh and similar settings.

\section{Methods}

This study was conducted within the Food and Agricultural Approaches to Reducing Malnutrition (FAARM) cluster-randomized controlled trial undertaken in two subdistricts of Habiganj District in Bangladesh's Sylhet Division (ClinicalTrials.gov ID: NCT025-05,711, Wendt et al. 2019). FAARM included 2700 women in 96 settlements who reported an interest in gardening and access to at least $40 \mathrm{~m}^{2}$ of land. The FAARM trial aims to evaluate 
the impact of a Homestead Food Production program implemented by the international non-governmental organization (NGO) Helen Keller International with the local NGO Voluntary Association for Rural Development (VARD). Alongside nutrition and hygiene education, the intervention promoted homestead production of nutritious foods among small-scale farmers, with the goal of improving garden productivity and dietary diversity, and eventually reducing child stunting. A survey conducted in 2014 in the FAARM project area among 64 households with existing home gardens revealed that poor or deteriorating soil fertility in gardens was considered a problem by $78 \%$ of families (Kern 2015).

\subsection{The BUNCH project}

The Biochar-Urine Nutrient Cycling for Health (BUNCH) feasibility study was designed to test whether urine-enriched biochar-based fertilizer was acceptable and could bolster FAARM participants' garden productivity. Starting in January 2016, FAARM participants were trained on preparing and using urine-enriched biochar-based fertilizers. In the winter season of 2016/2017, a selected number of farmers were asked to take part in participatory research using comparative field trials. The participants who took part in these trials were selected by FAARM field staff based on the availability of a suitable plot and their willingness to undertake a collaborative field trial. In each participant garden, one plot was treated with cow urine-enriched biochar fertilizer applied to the root zone once at planting using established methods (Cornelissen et al. 2016) and the adjacent plot was fertilized with the farmer's usual practices - typically cow manure or no additional fertilizer at all.

\subsection{Design and sampling}

This mixed-method assessment used four data sources: (1) in-depth interviews with field trial participants, (2) the FAARM baseline survey, (3) quantitative surveillance of FAARM participants who lived in areas where biochar-based fertilizer training had been offered, and (4) field trial results. The qualitative research was informed by a modified focused ethnography approach [see (Knoblauch 2005) and (Pelto and Pelto 1997) for theoretical examples], which focused on a specific issue (increasing garden crop production with urine-enriched biochar fertilizer), and addressing programmatic concerns related to that issue (use and acceptability of urine-enriched biochar among farmers), by engaging with those undertaking the intervention. The manuscript is structured on the themes found in the qualitative results, supplemented by the quantitative data.

In-depth interview respondents were recruited from households participating in the BUNCH farmer field trials during the 2016/2017 winter season to obtain insights from individuals with experience in the preparation and use of urine-enriched biochar. In February 2017, nine settlements were randomly sampled from the 14 intervention settlements where three or more farmers were enrolled in the current trials of biochar-based fertilizer. From these nine settlements, 26 households were selected and one person per household invited for interview. The in-depth interview respondents were the individuals from each household most involved in preparation and use of biochar-based fertilizer. In most cases, this was the woman enrolled in the FAARM trial, but if another household member was more involved, that person was interviewed.

The FAARM baseline survey was undertaken from March to May 2015 alongside enrollment into the FAARM trial and targeted to all enrolled trial participants. At the close of the BUNCH project in June/July 2017, biochar-based fertilizer had been introduced 
through trainings and field trials in 31 settlements and all FAARM participants living in these settlements were targeted with a short questionnaire collecting information on their experiences with biochar-based fertilizer. Of the 973 FAARM participants in this area at the time of this round of surveillance, 845 (87\%) completed the module.

Comparative field trials were undertaken in the winter season of 2016/2017 using two crops: cabbage and kohlrabi. In total, records indicate that 65 trials were begun with cabbage and 55 with kohlrabi; however, yield data were only obtained for 36 cabbage trials (55\%) and 39 kohlrabi trials (71\%), with only partial data obtained for one kohlrabi trial. For cabbage, the number of plants per plot ranged from 4 to 56 with plot size ranging from 1.1 to 14 square meters, while for kohlrabi the number of plants per plot ranged from 4 to 53 with plot size ranging from 0.85 to 5 square meters. Field trials were planned collaboratively between the field staff and the households, and planting was undertaken together in line with a written plan (Fig. 1, Panels A and B). Field trials were followed up and documented by field staff throughout the production period (Fig. 1, Panel C), and at harvest farmers visually compared production quantity between plots treated with biochar-based fertilizer and control plots (Fig. 1, Panel D), engaging them directly in the participatory research process.

\subsection{Training and data collection}

Two researchers from BRAC University's James P Grant School of Public Health designed the qualitative data collection tools and subsequently conducted the in-depth interviews. Both are public health graduates with previous training in qualitative research and experience in the topics of agriculture and nutrition. The BUNCH research team conducted iterative revisions of the interview guides, prepared the field plan and discussed critical objectives prior to data collection. The interview guide included open-ended questions about experiences, perceptions, and challenges of preparing and using urine-enriched biochar fertilizer with the objective to determine perceived benefits that may serve as drivers to adopt new practices and to identify potential barriers. Topics also included issues related to gender dynamics in preparation and use of biochar-based fertilizer (e.g., roles and responsibilities and ability to prepare and use the fertilizer).

Qualitative data were collected over a two-week period in February 2017, during the harvest period for the field trials. Following receipt of written informed consent, 25 semistructured interviews were completed, out of the target of 26 . The overall sample was designed to reach "meaning saturation," defined as the point when not only salient themes but also the meaning behind them can be understood (Hennink et al. 2017). The sample was not stratified by respondent characteristics. Respondents were interviewed in a private place of their choice with no other family members present.

The FAARM baseline survey was targeted to all women enrolled in the FAARM trial by professional short-term data collectors, who received a comprehensive training with multiple field practice sessions before field work began. Data were collected using Open Data Kit on tablets (Anokwa et al. 2009). Of the 1302 women enrolled in FAARM intervention areas at baseline, 1295 were in a household surveyed in the baseline modules used in this manuscript (99\%). After the survey, we followed up with women missed at baseline and collected additional data on the education level of women and the religion of households, resulting in data for 1302 and 1301 women, respectively.

Quantitative surveillance data were collected by nine professional, full-time data collectors during one round of routine FAARM surveillance during May/June 2017 using 

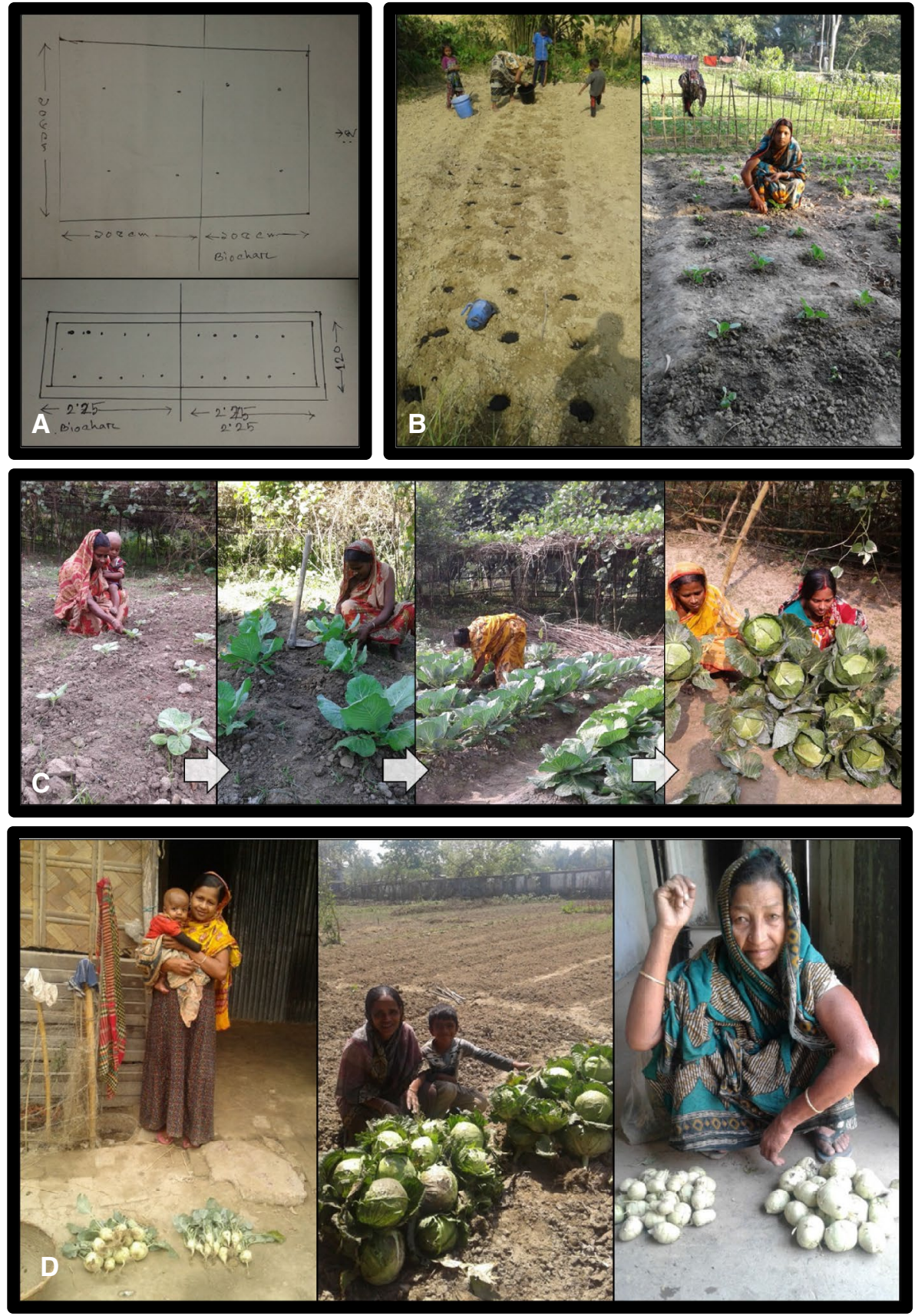

Fig. 1 Field trial setup and tracking. A Field trials were designed in collaboration with participant farmers and were designed for the treatment (biochar-based fertilizer) and control (usual practice) plot to be of the same size. B Field trials were planted with project staff present and were documented. C Field trials were followed up intermittently over the course of the growing season and crop health was evaluated. D At harvest, participant farmers were encouraged to compare production visually and crops were weighed 
Open Data Kit on tablets as outlined in the FAARM protocol (Wendt et al. 2019). The setup of the field trials was recorded using mobile phones by FAARM implementation staff (Anokwa et al. 2009). Final field trial results were weighed on a locally available electronic produce scale (Vision Power, $2 \mathrm{~g}$ precision) by FAARM implementation staff and recorded on paper sheets.

\subsection{Data management and analysis}

During qualitative data collection, interviews were summarized in field notes and audiorecorded. After transcription in Bangla, data were managed and coded using Atlas. ti 6.0 (ATLAS.ti Scientific Software Development GmbH 1999). First, codes were assigned deductively drawing on sections from the interview guide (e.g., perceptions of urine, biochar production, fertilizer preparation), followed by inductive coding to identify new themes. To improve intercoder reliability, selected transcripts were coded by both members of the research team and cross-checked for consistency. In instances of inconsistency, the team convened with an experienced researcher at BRAC University, referred to the audio recordings, and collectively determined a solution. Analysis results and relevant quotes were translated into English during manuscript production.

All quantitative data were managed and analyzed using Stata 15.1 (StataCorp 2017), after downloading from Open Data Kit or entry into spreadsheet software. Most quantitative data were analyzed as collected with limited indicator construction. From household asset information, we estimated each household's position within the 2014 Demographic and Health Survey national wealth quintiles using Equity Tool guidelines (National Institute of Population Research and Training-NIPORT/Bangladesh et al. 2016; Metrics for Management 2016). The number of crops produced by each household included all crop types grown in both field and garden the year before the baseline survey. Quantitative data are presented using means and proportions. When undertaken, p-values were calculated using a Wald test adjusted for settlement-level clustering. For field trial analysis, impact estimates were calculated per farmer and then averaged over the sample as a whole.

\section{Results}

The areas in which the BUNCH project introduced biochar-based fertilizer were similar to the other FAARM intervention areas in religion, wealth, land ownership, and education of enrolled women (Table 1). However, farmers in the BUNCH areas had greater agricultural crop diversity with approximately two more types of crops produced at baseline compared to FAARM areas where BUNCH was not active. By June 2017, 79\% of FAARM participants in BUNCH areas had heard of biochar-based fertilizers with nearly all of those who heard $(93 \%)$ having attended a training and $73 \%$ reporting using biochar-based fertilizer in their fields (Table 2).

The FAARM participants in BUNCH areas that agreed to conduct a BUNCH field trial had more land and agricultural crop diversity than other households in these areas (Table 1). In-depth interview respondents were a subsample of the field trial participants. 


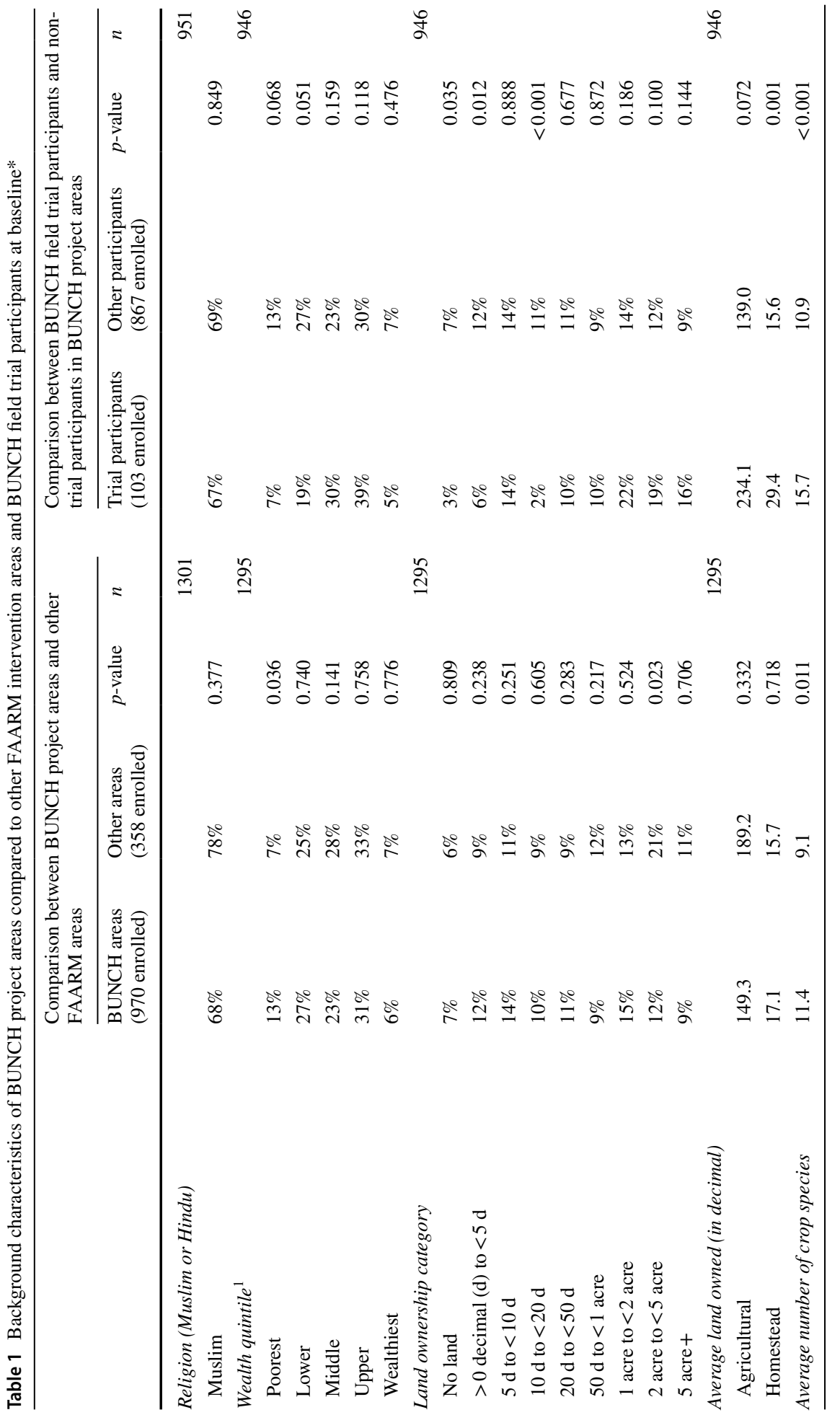




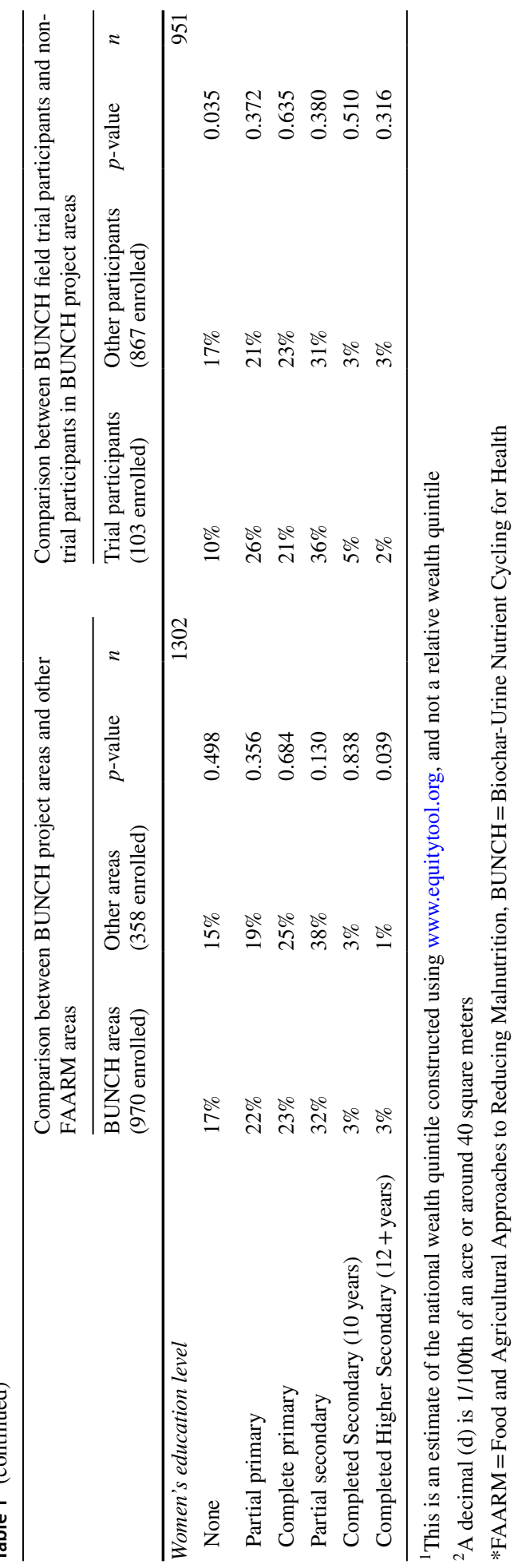


Table 2 Experience with biochar-based fertilizer in BUNCH project areas in Habiganj, Bangladesh (May/ June 2017)

Percentage

All interviewed $(n=845)$

Heard of biochar

Of those that heard of biochar $(n=666)$

Attended a training

Used biochar-based fertilizer biochar

Of those who attended a training, confidence in making biochar $(n=618)$

Already doing

Very confident

Confident

Unsure/maybe

Could not do it

Of those that used biochar-based fertilizer $(n=489)$

Plan to continue

Of those that heard of biochar but have not used it, why? $(n=177)$

Don't wish to

Not able to

No time

Plan to make biochar in future

No cow

Not enough land

${ }^{*} B U N C H=$ Biochar-Urine Nutrient Cycling for Health

Table 3 Background characteristics of in-depth interview respondents in Habiganj, Bangladesh $(n=25)$

\begin{tabular}{lc}
\hline Characteristic & Number $(\%)$ \\
\hline Age & \\
$\leq 24$ years & $10(40)$ \\
$25-34$ years & $4(16)$ \\
35-44 years & $5(20)$ \\
$\geq 45$ years & $6(24)$ \\
Gender & \\
Female & $21(84)$ \\
Male & $4(16)$ \\
Religion & \\
Muslim & $20(80)$ \\
Hindu & $5(20)$ \\
\hline
\end{tabular}

All respondents participated in the Biochar-Urine Nutrient Cycling for Health (BUNCH) field trials

All 25 respondents were married, their ages ranged from 19 to 60 years, and they resided in households where agriculture was the main occupation of the household head (Table 3). 


\subsection{Perceptions of cow urine for agriculture and cow versus human urine}

Using cow urine for farming was described as acceptable by all respondents. Among Hindu respondents, cows were described as sacred, pure and Vogoban (akin to god) and this clean and revered status extended to cow urine. Cow urine use in home gardens was acceptable because people already came in contact with cow urine and cow dung in their daily lives, for example, when removing urine and dung from homestead areas, gathering cow dung and preparing it for fuel use, and using cow dung as a plaster-polishing agent for walls and floors. Cow urine was viewed as having nutrients that support plant growth, and several respondents lauded its ability to purify impure objects.

In contrast to the acceptability of cow urine as a fertilizer, human urine was largely deemed unacceptable, being described as "impure," "unholy," "a toxic agent," "stinking," "disgusting," and a source of disease. Respondents described human urine as inappropriate for food production. To describe human urine's impure and unholy nature, Hindu respondents used the word Oshuchi; Muslim respondents used the word Napak. When pressed to gauge their openness to nevertheless using human urine, respondents emphasized that they would be subjected to social stigma if they were to use human urine in their gardens. Only a few respondents were open to the possibility of using human urine-enriched biochar as a fertilizer if the advice came from service providers or experts, and if respondents could see that it improves crop production.

\subsection{Experience of preparing and using cow urine-enriched biochar fertilizer}

In the in-depth interviews, respondents were able to describe the fertilizer preparation following the same (or similar) steps as conveyed during trainings (Fig. 2). The materials most commonly used as feedstock for biochar production were dry fallen leaves and rice straw, both freely available. In the quantitative surveillance, of the 618 participants who had attended a training on biochar-based fertilizer, 38\% stated they were confident or very confident to make biochar on their own and a further $50 \%$ stated they were already making biochar-based fertilizer, while the remaining $12 \%$ reported they were unsure in their ability or could not produce biochar-based fertilizer on their own (Table 2).

\subsubsection{Household dynamics of biochar-based fertilizer preparation}

Qualitative interviews with female respondents found that they had ususally consulted husbands and mothers-in-law for approval and permission to participate in the field trials. A minority of respondents said their family members were initially reluctant to approve and adopt this new method of fertilization because it was unfamiliar, although they eventually incorporated it into their home gardening practices for the field trials.

In some households, other family members, including husbands, helped to prepare the urine-enriched biochar. In general, males and females, when both were engaged, carried out different activities to make the urine-enriched biochar. In instances when men helped, men engaged in digging holes and setting and dousing fires while women gathered feedstock and water. Urine collection was a key task in this process and could 

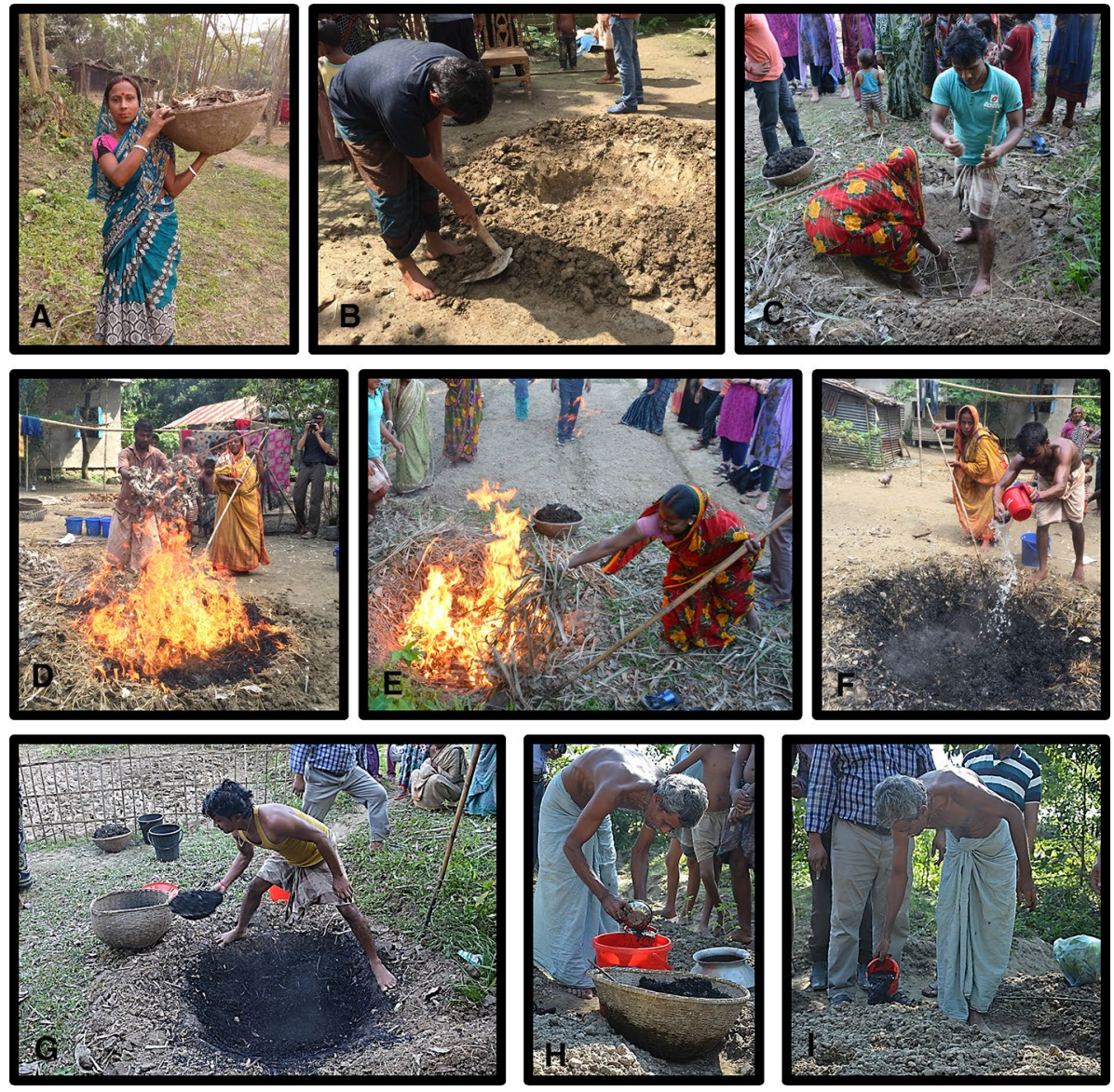

Fig. 2 Steps to produce and use cow-urine-enriched biochar fertilizer. (A detailed manual is available from the corresponding author upon request.) These steps can be completed in one day and the fertilizer can be used immediately: A Collect biomass feedstock, such as dry leaves and rice straw, from one's home or nearby sites. B Dig a shallow kiln hole in the soil. C Arrange a well aerated feedstock pile at the bottom of the kiln. D Start a fire at the top of the feedstock pile. E Once the fire is hot, having carbonized the lower parts of the feedstock pile, slowly add feedstock layer by layer to be carbonized by the heat of the fire curtain formed above the feedstock. F Douse the carbonized feedstock with water to stop the fire and carbonization. G Collect the biochar. $\mathbf{H}$ Mix the resulting biochar with cow urine to create urine-enriched biochar fertilizer (using a 1:1 ratio). I Apply urine-biochar fertilizer to the root zone of new plants

be challenging for families who did not have their own cows. Respondents reported that they did not need to spend money to obtain cow urine, but collected it either from their own cow or from their neighbors' cow free of cost, using the drainage system in the cow shed. In these cases, husbands or other male family members usually took the responsibility of collecting cow urine from neighbors and relatives because women were not permitted to visit other homes without a male relative. In some instances, mothers-inlaw performed this task with the help of male family members. 


\subsubsection{Perceived benefits}

Reported perceived benefits of urine-enriched biochar fertilizer in home gardening were related to increases in yields and income, low input costs, access to safe and nutritious foods, and a general sense that the process was convenient and feasible. Overall, respondent households grew and applied biochar-based fertilizer to multiple crops, including cabbage, kohlrabi, radish, cauliflower, field bean, wax gourd, eggplant, okra, spinach, and bottle gourd.

Money was saved because the fertilizer could be made on the farm with no additional financial resources required. Making fertilizer on the farm or homestead was also perceived as convenient because the frequency of travel to markets for purchasing synthetic fertilizers was reduced. Women described this as particularly important because they would otherwise need to rely on a male relative to bring it home from the market or accompany them there, which restricts accessibility. In this regard, women discussed how the production and use of urine-enriched biochar fertilizer contributed to building a sense of self-reliance, because it was a quality product made by themselves that they had immediate access to and with which they could increase garden yields.

We can prepare this kind of good fertilizer without spending any money and only by putting in a little labor. We are women and cannot go to the market whenever we need. For this fertilizer, we don't need to go to the market, we don't need to ask others to bring fertilizer from the market, and we are able to do this by ourselves. (Female respondent, Age: 38 years).

The organic nature of urine-enriched biochar fertilizer was another reason respondents favored it. They noted the absence of "chemicals" and that biochar-based fertilizers left no "chemical residue" on vegetables, were "not poisonous," and gave vegetables "a better taste."

It is better to use homemade fertilizer than using fertilizer that we buy from the market. The vegetables that we produce by using this fertilizer [urine-enriched biochar] are chemical-free and we can consume these without hesitation. Moreover, vegetables that we previously grew using white fertilizer [urea] were not as tasty as these vegetables. (Female respondent, Age: 25 years).

The positive attributes ascribed to vegetables grown with biochar-based fertilizer translated into financial capital by earning income from surplus production, as well as social capital by being able to share extra produce with neighbors, friends, and family members. This bolstered a sense of pride, as did the admiration their gardens received from others. Nearly all respondents described feeling motivated to continue using biochar-based fertilizer regardless of the continuation of the project. In surveillance, $99 \%$ of those that tried the technology reported that they planned to continue to use biochar-based fertilizers (Table 3).

We have found interest and hope. In future, we will do this again. Now we are free from poisonous things. It required physical labor, but it has no cost. (Female respondent, Age: 22 years).

I grew radish. The sale of radishes was quite good. We offered some of those vegetables to our relatives too. They ate those and requested us to send more [amazed look]. (Female respondent, Age: 22 years). 


\subsubsection{Field trial results}

In-depth interview respondents noted greater food crop production in the plots fertilized with urine-enriched biochar compared to those fertilized with usual methods. Usual methods mentioned included kitchen ash, mineral fertilizers (urea/sada saar, potash/lal saar, and phosphate/maitta saar), cow dung (gobor/leda) poultry manure (haas-murgir bit), compost, and lowland soil. Interview respondents also stated that the increased productivity of their plots was due to the new application of biochar-based fertilizer, which allowed for more food to be fed to the family and more produce to be sold for income generation.

Field trial results supported these reported experiences: They indicated sizable yield benefits from using biochar-based fertilizer for both cabbage and kohlrabi (Table 4), compared to usual practice control plots-in which a few farmers used cow dung and most used no fertilizer. Under the biochar-based fertilizer treatment, biochar and urine were mixed at a 1:1 (volume) ratio and the mixture applied at volumes from 1.15 to $3 \mathrm{~L}$ per square meter, with $2 \mathrm{~L}$ per square meter being the most common application level [which corresponds to $20 \mathrm{~m}^{3}$ / ha of urine-biochar substrate; and approximately $2 \mathrm{t}$ (dry matter) biochar/ha]. The comparative results were often visible to the naked eye (Fig. 1, Panel D), and all farmers had greater levels of production in biochar-based fertilizer plots compared to control plots.

While the number of plants harvested in biochar-based fertilizer plots was only slightly higher than in usual practice plots, with relatively weak statistical evidence for a difference, there was very strong evidence $(p<0.001)$ for an increase in vegetable size, with vegetables from the urine-biochar plots approximately $50 \%$ heavier than those from control plots (range $10 \%$ to $200 \%$ for cabbage and $0 \%$ to $190 \%$ for kohlrabi). In absolute terms: The average cabbage weighed $361 \mathrm{~g}$ more $(1061 \mathrm{~g}$ vs. $700 \mathrm{~g})$ and the average kohlrabi weighed $79 \mathrm{~g}$ more ( $241 \mathrm{~g}$ vs. $163 \mathrm{~g}$ ). Total harvested vegetable weight per plot increased by about two-thirds and vegetable weight per area by about $60 \%(p<0.001)$. In absolute terms: For cabbage, total vegetable yield per square meter was $1.6 \mathrm{~kg}$ higher $(4.25 \mathrm{~kg}$ vs. $2.65 \mathrm{~kg}$ ), and for kohlrabi, total vegetable yield per square meter was $0.8 \mathrm{~kg}$ higher $(2.1 \mathrm{~kg}$ vs $1.3 \mathrm{~kg})$ in the urine-biochar fertilized plots compared to controls.

\subsubsection{Perceived barriers}

Only a few respondents did not own one or more cows and those that did not own a cow collected cow urine from neighbors and relatives. As stated earlier, women from households without a cow often had to wait for their husbands to collect the urine from outside the homestead. Some respondents with no cow described difficulties carrying urine from distant places, and convincing neighbors of their need for cow urine. Additionally, some respondents said they had limited access to the biomass feedstock (mainly rice straw and dry leaves) needed to make the biochar.

Quantitative results largely agree with these qualitative findings. Of the respondents who had heard about biochar-based fertilizers but had not yet tried it (27\% of those that had heard, Table 3) $29 \%$ stated disinterest as their primary reason for not trying the technology, one-fifth reported that lack of land was a barrier and $8 \%$ stated that lack of a cow was an impediment to trying the new method. 


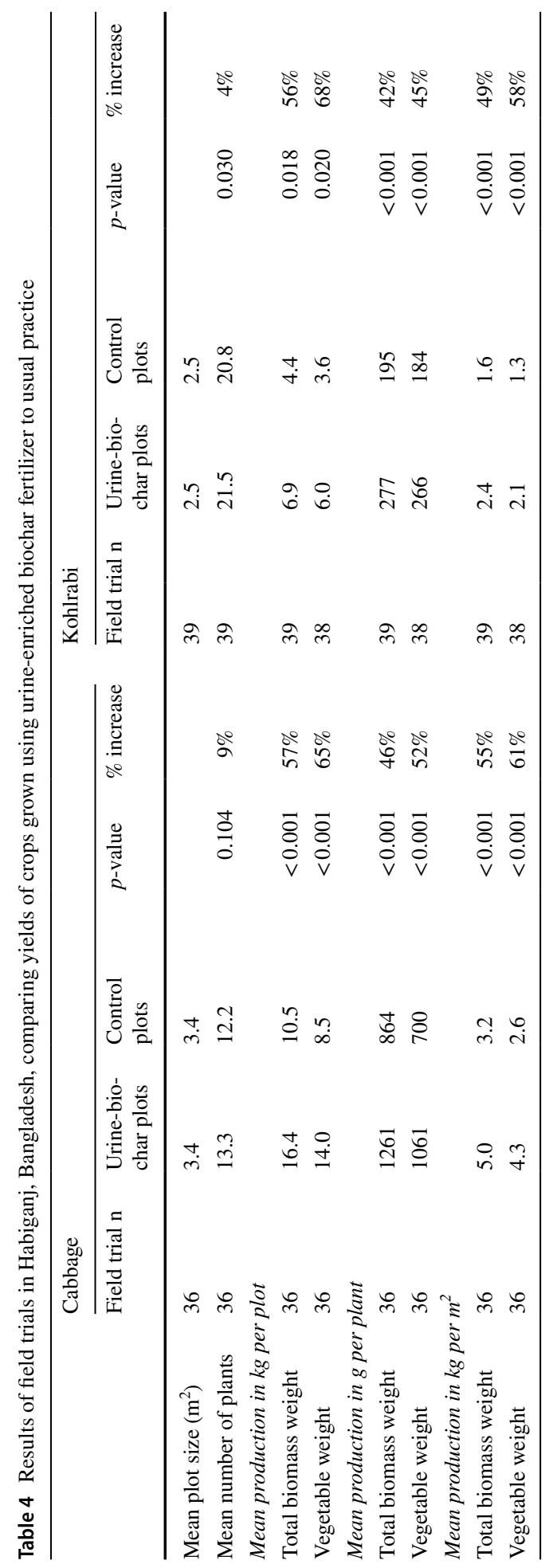




\section{Discussion}

This manuscript, based on the BUNCH project, is the first to describe Bangladeshi farmers' experiences in preparing and using cow urine-enriched biochar fertilizer for agricultural purposes, its acceptability for use in food crop production, and the perceived and measured benefits and possible barriers that affect adoption. We also explored the acceptability of human urine in food production in Bangladesh. Respondents in the in-depth interviews and quantitative survey described relative ease of use in preparing cow urine-enriched biochar, and they appreciated that biochar-based fertilizer produced greater yields than their accustomed methods of fertilization. These findings were supported by farmer field trial results, which showed yield increases of approximately $60 \%$.

A potential issue that may preclude the adoption of this new method is the acceptability of using urine in food production (Mariwah and Drangert 2011). In this study, we found a willingness to use cow urine as an ingredient in fertilizer, based on cultural practices that normalize the use of cow dung in everyday domestic tasks and the physical contact that cow owners have with the urine during daily removal of cow waste. A cultural understanding that cow urine is not untouchable or impure supports its use in everyday life. The perceived social risks of using it are minimal as there was no evidence of sociocultural beliefs that would proscribe its use in food production.

We found that human urine was considered unacceptable for use in food production in our setting in northeastern Bangladesh. This aligns with findings from previous studies and reflects broader social norms that proscribe the handling of human urine (Mariwah and Drangert 2011; GTZ 2004; Andersson 2015). Respondents in this study perceived several risks from using human urine in food production (e.g., social stigma, religious impurity, and disease) that outweighed the potential benefits, making them unwilling to experiment with human urine. In response to this finding, we modified our training messaging to recommend cow urine as a more acceptable option in this context. In contrast, a study in Uganda undertook a collective action process that ultimately led farmers to state their willingness to try human urine to improve soil fertility (Andersson 2015). Future studies on acceptability and use of human urine may consider a collective action approach to increase adoption.

As wood is scarce and thus expensive in Bangladesh, farmers mainly used rice straw and dry fallen leaves as biochar feedstock in our area. While rice straw and certain leaves can also be used as animal feed or bedding, and rice straw for dung sticks used as fuel, there is generally a surplus of these materials in the area, making them accessible free of charge. An additional benefit was the resulting biochar's powdery consistency, thus eliminating the need for grinding before mixing with urine.

Several domains of perceived benefits of using cow urine-enriched biochar fertilizer in food production were identified, including financial, social, and health benefits and a heightened sense of self-efficacy. These findings echo those of a recent qualitative evaluation on adoption of improved horticulture practices, including homemade compost fertilizer, by women in coastal Bangladesh (SPRING 2017). For poor households, the financial gains through cost reduction in inputs and food purchased, and the income generated from sale of surplus produce, translate into a meaningful return on the minimal economic and time investment for producing the fertilizer. Similarly, the smallholder farming households in this study recognized a gain in access to more nutritious and healthy foods for their own consumption through higher yields from using organic biochar-based fertilizer. 
Biochar-based fertilization resulted in substantial yield increases in our setting, in line with biochar amendment's positive effects on crop productivity in the tropics. Our increases were larger in magnitude than the $25 \%$ yield increase in the tropics reported in a global meta-analysis of 527 comparisons where only biochar but not biochar-based fertilizers were applied (Jeffery et al. 2017). The higher yields achieved by farmers participating in our study could be expected as we enriched the applied biochar with urine as a nutrient. Limited literature exists that compares the effect of organically enriched biochar (like urine-biochar or compost-biochar) with usual farmer practice. In multi-arm field trials in two villages in Nepal, urine-enriched biochar was compared to diluted urine alone and doubled to tripled cabbage yields (162\% and 195\% increase) (Schmidt et al. 2017), which is far higher than the $65 \%$ improvements seen in our cabbage field trials, even though most farmers in our study used nothing and few used cow dung in their control plots. Gains from biochar amendment are expected to be larger in places with poorer soils (Igalavithana et al. 2015), which is likely a more severe problem in Nepal, although farmers in our study area also reported low soil fertility as a problem in home gardens (Kern 2015).

All farmers in our study obtained yield benefits from organic biochar-based fertilization, likely contributing to the survey result that nearly all farmers who had tried biochar-based fertilization reported that they planned to continue. The increased production not only translated into financial and health benefits but was also perceived to improve social capital. In communities where reciprocity is fundamental to food security, having the means to share produce with relatives and neighbors aligns with social obligations and increases chances of receiving support in times of need. The study also offered insights into contextspecific barriers to preparing and using cow urine-enriched biochar, namely that routine access to cow urine and biomass feedstock for biochar production can be challenging for some, with $8 \%$ of those who had been exposed to the technology but not yet used it stating this reason.

The skills women gained, combined with the increased quantity and improved quality of garden produce and the resulting financial and health gains, translated into a perception of self-efficacy-a belief in their ability to successfully produce vegetables, earn income, and safeguard the health of their families. This along with reported improvements in social capital and autonomy in income show potential for this intervention to improve aspects of women's empowerment, which we define (using Kabeer's framework) as the ability for an individual to make strategic choices using the concepts of resources, agency, and achievements. In our study, we found improvements described in all three aspects: resources (e.g., social capital), agency (e.g., self-efficacy), and achievements (e.g., improved yields and income) (Kabeer 1999, 2005). Gains that were described were made within local gender norms and constructs. The trainings were not specifically designed to address gender issues or be gender transformative. However, they focused on women and the technology was adapted to a household scale for use in home gardening-an activity usually in the "women's sphere" of household division of labor. Similar programs in Bangladesh focusing on homestead food production have also shown improvements in self-efficacy (SPRING 2017) and decision-making power within the household over time (Bushamuka et al. 2005).

In addition, several respondents discussed how they received support from family members in preparing and using cow-urine-enriched biochar fertilizer. Activities such as making biochar-based fertilizer as part of a broader homestead gardening program can provide a platform from which to promote sharing of workloads and responsibilities among household members and improving household communications. Recent and current agriculture and nutrition programs in Bangladesh and elsewhere have shown promising results when aligning agriculture with a gender and social transformative approach (Hillenbrand 2010; 
Nordhagen et al. 2017). In households where husbands or decision-makers are not supportive either initially (giving permission) or over time, this may be a barrier for adoption or sustained participation as men's support (permission, gathering biomass/urine from neighbors) is critical to the process. This highlights the importance of implementing this intervention-and any others where women are the primary adopters-with the involvment of the entire household in order to encourage buy-in and collaboration.

Overall, our findings support that agricultural technology adoption is not merely teaching the same thing in a different place rather is strengthened by taking into account local contexts, including economic, social, and cultural conditions (Wigboldus et al. 2016). The use of collaborative field trials in the BUNCH project demonstrates how we sought to enable farmers to judge for themselves the usefulness of the innovation. Using the theory proposed by Glover et al. 2019, we used a mixed-method approach to examine farmers' perceptions of acceptability/feasibility and their decision to make and use urine-enriched biochar (disposition and response). From these findings, we then identified critical points that serve to inform future iterations of trainings (propositions) including adaptions to raw materials used (e.g., encouraging cow urine when more socially acceptable), methods (e.g., including discussions of where items could be obtained for households without ready access), and mode of engagement (e.g., targeting the entire household to promote buy-in and participation from different household members during the preparation steps) (Glover et al. 2019).

Several limitations merit consideration when interpreting these results. Although interviews were conducted in the absence of project staff, the possibility of reporting bias cannot be excluded as researchers were guided to participant households by project staff. The survey questions, however, were asked to all enrolled FAARM participants in BUNCH areas and conducted without involvement of project staff, but respondents may still have felt it socially desirable to give good feedback about the project. Additionally, this study may not accurately reflect a natural scenario of adoption of new practices because the participants interviewed were knowingly engaged in a research project after having committed to using urine-enriched biochar (although they refused to use human urine). Plot management during field trials was done by the households, and as there was no blinding, it cannot be ruled out that there were differences in treatment between the two types of plots apart from the fertilization method. Data collection for field trials was done by project staff and not by research staff, with possible implications for data quality.

\section{Conclusions}

This study showed that cow urine-enriched biochar fertilizer was considered advantageous by the Bangladeshi smallholder farmers in the study area. Participants were motivated to continue using cow urine-enriched biochar fertilizers after the project ended because it was viewed as inexpensive to implement, chemical-free, effective in improving garden yields and enhancing the tastiness of vegetables, and relatively straightforward to prepare-as ingredients can be sourced locally and at low or no monetary cost. Farmer trials showed significant yield increases of approximately $60 \%$.

Given its potential to improve soil fertility and increase crop yields, and thus to improve food security and dietary diversity, while enhancing financial and social capital and bolstering female autonomy, cow urine-enriched biochar is an exceptionally promising 
technology that should be investigated further and tested at larger scale in Bangladesh and other countries.

Acknowledgements We want to thank all the project staff of BUNCH, FAARM, Helen Keller International and Voluntary Association for Rural Development (VARD) for their support in conducting this study. Our sincere gratitude goes in particular to the field facilitators of VARD for their helpfulness and cooperation in field management during the data collection. Finally, we would like to thank our study respondents and their family members for sharing their valuable time and experiences with us.

Funding Open Access funding enabled and organized by Projekt DEAL. We thank the Leveraging Agriculture for Nutrition in South Asia (LANSA) research consortium funded by UK aid from the UK government for their support under the Responsive Window for funding the "Biochar-Urine Nutrient Cycling for Health" (BUNCH) project, the Nutrition Embedding Evaluation Programme (NEEP) funded by the UK Department for International Development (DFID) through PATH International (grant number: DFI.1836-705713-PRE) for their support in our surveillance system, and the German Federal Ministry of Education and Research (BMBF) for supporting the parent study "Food and Agricultural Approaches to Reducing Malnutrition" (FAARM) (Award number 01ER1201).

\section{Compliance with ethical standards}

Conflict of interest The authors declare that they have no conflict of interest.

Ethical approval This study received ethical approval from the Institutional Review Board (IRB) of James P Grant School of Public Health, BRAC University, Bangladesh. All procedures performed in studies involving human participants were in accordance with the ethical standards of the 1964 Helsinki declaration and its later amendments or comparable ethical standards. Informed written consent was obtained from all individual participants included in the study after clarifying the study objective and voluntary nature of participation. Confidentiality and anonymity were also ensured. Permission was also taken before audio recording.

Informed consent Informed consent was obtained from all individual participants included in the study.

Open Access This article is licensed under a Creative Commons Attribution 4.0 International License, which permits use, sharing, adaptation, distribution and reproduction in any medium or format, as long as you give appropriate credit to the original author(s) and the source, provide a link to the Creative Commons licence, and indicate if changes were made. To view a copy of this licence, visit https://creativecommons. org/licenses/by/4.0/. The images in this article are not included in the article's Creative Commons licence, but are under a Creative Commons non-commercial licence (CC BY-NC). To view a copy of the figures' license, visit https://creativecommons.org/licenses/by-nc/4.0/.

\section{References}

Ali, A. M. S. (2005). Homegardens in smallholder farming systems: Examples from Bangladesh. Human Ecology, 33, 245-270. https://doi.org/10.1007/s10745-005-2434-8.

Andersson, E. (2015). Turning waste into value: Using human urine to enrich soils for sustainable food production in Uganda. Journal of Cleaner Production, 96, 290-298. https://doi.org/10.1016/j.jclep ro.2014.01.070.

Anokwa, Y., Hartung, C., Brunette, W., Borriello, G., \& Lerer, A. (2009). Open source data collection in the developing world. Computer, 42(10), 97-99. https://doi.org/10.1109/mc.2009.328.

Atkinson, C. J., Fitzgerald, J. D., \& Hipps, N. A. (2010). Potential mechanisms for achieving agricultural benefits from biochar application to temperate soils: A review. Plant and Soil, 337, 1-18. https://doi. org/10.1007/s11104-010-0464-5.

ATLAS.ti Scientific Software Development GmbH. (1999). ATLAS.ti. (6.0). Berlin: Scientific Software Development. 
Bélières, J., Bonnal, P., Bosc, P., Losch, B., Marzin, J., \& Sourisseau, J. (2015). Family farming around the world. Definitions, contributions and public policies. Paris: Agence Française de Développement (AFD).

Bushamuka, V. N., de Pee, S., Talukder, A., Kiess, L., Panagides, D., Taher, A., et al. (2005). Impact of a homestead gardening program on household food security and empowerment of women in Bangladesh. Food and Nutrition Bulletin, 26, 17-25. https://doi.org/10.1177/156482650502600102.

Cerf, M., Jeuffroy, M. H., Prost, L., \& Meynard, J. M. (2012). Participatory design of agricultural decision support tools: Taking account of the use situations. Agronomy for Sustainable Development, 32, 899-910. https://doi.org/10.1007/s13593-012-0091-z.

Cornelissen, G., Pandit, N. H., Taylor, P., Pandit, B. H., Sparrevik, M., \& Schmidt, H. P. (2016). Emissions and char quality of flame-curtain "Kon Tiki" Kilns for farmer-scale charcoal/biochar production. PLoS ONE, 11, e0154617. https://doi.org/10.1371/journal.pone.0154617.

Diacono, M., \& Montemurro, F. (2011). Long-Term effects of organic amendments on soil fertility. In E. Lichtfouse, M. Hamelin, M. Navarrete, \& P. Debaeke (Eds.), Long-Term effects of organic amendments on soil fertility (pp. 761-786). Dordrecht, Netherlands: Springer.

Doss, C. (2015). Women and agricultural productivity: What does the evidence tell us? Economic growth center discussion paper no. 1051.

Elferink, M., \& Schierhorn, F. (2016). Global Demand for Food Is Rising. Can We Meet It? Retrieved August 27, 2017, from https://hbr.org/2016/04/global-demand-for-food-is-rising-can-we-meet-it.

FAO. (2014). The state of food and agriculture. Innovation in family farming. Rome: Food and Agriculture Organization of the United Nations FAO.

FAO. (2016). Bangladesh country fact sheet on food and agriculture policy trends. Rome, Italy: Food and Agriculture Organization of the United Nations (FAO).

Feder, G., Just, R. E., \& Zilberman, D. (1985). Adoption of agricultural innovations in developing countries: A survey. Economic Development and Cultural Change. https://doi.org/10.1086/451461.

Gebre, G. G., Isoda, H., Rahut, D. B., Amekawa, Y., \& Nomura, H. (2019). Gender differences in the adoption of agricultural technology: The case of improved maize varieties in southern Ethiopia. Women's Studies International Forum. https://doi.org/10.1016/j.wsif.2019.102264.

Gibson, J. J. (1979). The ecological approach to visual perception. Boston: Houghton Mifflin.

Glover, D., Sumberg, J., Ton, G., Andersson, J., \& Badstue, L. (2019). Rethinking technological change in smallholder agriculture. Outlook on Agriculture, 48(3), 169-180. https://doi.org/10.1177/0030727019 864978.

Glover, D., Venot, J. P., \& Maat, H. (2017). On the movement of agricultural technologies: Packaging, unpacking and situated reconfiguration. In J. Sumberg (Ed.), Agronomy for development: The politics of knowledge in agricultural research (pp. 14-30). London, UK: Routledge.

Graeub, B. E., Chappell, M. J., Wittman, H., Ledermann, S., Kerr, R. B., \& Gemmill-Herren, B. (2016). The state of family farms in the world. World Development, 87, 1-15. https://doi.org/10.1016/j.world dev.2015.05.012.

GTZ (2004). Ecosan-Closing the Loop. Proceedings of the 2nd international symposium, 7th-11th April 2003, Lübeck, Germany (Ecosan-Closing the Loop. Proceedings of the 2nd International Symposium). Eschborn, Germany: Deutsche Gesellschaft für Technische Zusammenarbeit (GTZ) GmbH.

Hennink, M. M., Kaiser, B. N., \& Marconi, V. C. (2017). Code saturation versus meaning saturation: How many interviews are enough? Qualitative Health Research, 27(4), 591-608. https://doi. org/10.1177/1049732316665344.

Hernandez, E., Riquet, C., \& Anderson, J. (2017). Understanding the Demand for Financial, Agricultural, and Digital Solutions from Smallholder Households: Insights from the Household Survey in Bangladesh. Washington, DC, USA: Consultative Group to Assist the Poor (CGAP).

Hillenbrand, E. (2010). Transforming gender in homestead food production. Gender \& Development, 18, 411-425. https://doi.org/10.1080/13552074.2010.521987.

IAASTD (2009). Global report. Washington, DC, USA: International assessment of agricultural knowledge, science and technology for development (IAASTD).

Igalavithana, A. D., Ok, Y. S., Usman, A. R. A., Al-Wabel, M. I., Oleszczuk, P., \& Lee, S. S. (2015). The effects of biochar amendment on soil fertility. In M. Guo, Z. He, \& M. Uchimiya (Eds.), Agricultural and environmental applications of biochar: Advances and barriers. WI: Madison.

Jeffery, S., Abalos, D., Prodana, M., Bastos, A. C., van Groenigen, J. W., Hungate, B. A., et al. (2017). Biochar boosts tropical but not temperate crop yields. Environmental Research Letters. https://doi. org/10.1088/1748-9326/aa67bd.

Jönsson, H., Stintzing, A. R., Vinnerås, B., \& Salomon, E. (2004). Guidelines on the Use of Urine and Faeces in Crop Production. Stockholm, Sweden: EcoSanRes Programme and Stockholm Environment Institute (SEI). 
Kabeer, N. (1999). Resources, agency, achievements: Reflections on the measurement of women's empowerment. Development and Change, 30(3), 435-464. https://doi.org/10.1111/1467-7660.00125.

Kabeer, N. (2005). Gender equality and women's empowerment: A critical analysis of the third millennium development goal 1. Gender and Development, 13(1), 13-24. https://doi.org/10.1080/1355207051 2331332273.

Kern, S. (2015). Food-plant diversity in homegardens and its contribution to family nutrition-a case study from Rural North-eastern Bangladesh., University of Hohenheim, Stuttgart, Germany.

Klerkx, L., Schut, M., Leeuwis, C., \& Kilelu, C. (2012). Advances in knowledge brokering in the agricultural sector: Towards innovation system facilitation. IDS Bulletin, 43, 53-60. https://doi.org/10.111 1/j.1759-5436.2012.00363.x.

Knoblauch, H. (2005). Focused Ethnography. In Forum Qualitative Sozialforschung/Forum: Qualitative Social Research. https://doi.org/10.17169/fqs-6.3.20.

Kookana, R. S., Sarmah, A. K., Van Zwieten, L., Krull, E., \& Singh, B. (2011). Chapter three-Biochar application to soil: Agronomic and environmental benefits and unintended consequences. Advances in Agronomy, 112, 103-143. https://doi.org/10.1016/B978-0-12-385538-1.00003-2.

Lal, R., \& Khurana, A. (2011). Gender issues: The role of women in agriculture sector. International Journal of Business Economics \& Management Research, 1(1), 29-39.

Mariwah, S., \& Drangert, J. (2011). Community perceptions of human excreta as fertilizer in Peri-Urban agriculture in Ghana. Waste Management \& Research, 29, 815-822. https://doi.org/10.1177/07342 42X10390073.

Metrics for Management (2016). Bangladesh equity tool. www.equitytool.org/bangladesh.

Molden, D., Frenken, K., Barker, R., de Fraiture, C., Mati, B., Svendsen, M., et al. (2007). Trends in water and agricultural development. In D. Molden (Ed.), Water for food, water for life: A comprehensive assessment of water management in agriculture (pp. 57-89). London, United Kingdom: Earthscan.

National Institute of Population Research and Training-NIPORT/Bangladesh, Mitra and Associates, \& ICF International. (2016). Bangladesh demographic and health survey 2014. Dhaka, Bangladesh: NIPORT, Mitra and Associates, and ICF International.

Naved, R. T., Khan, N. N., Rahman, M. H., \& Ali, K. L. (2011). A rapid assessment of gender in agriculture of Bangladesh. Dhaka, Bangladesh: ICDDR, B.

Nordhagen, S., Tort, C. B., Kes, A., \& Winograd, L. (2017). Nurturing Connections? Evaluating the impact of a women's empowerment curriculum in Cote d'Ivoire. ICRW working paper. Washington, DC, USA: International Center for Research on Women (ICRW).

Ogunlela, Y. I., \& Mukhtar, A. A. (2009). Gender issues in agriculture and rural development in Nigeria: The role of women. Humanity and Social Sciences Journal, 4(1), 19-30.

Pelto, P. J., \& Pelto, G. H. (1997). Studying knowledge, culture, and behavior in applied medical anthropology. Medical Anthropology Quarterly, 11, 147-163. https://doi.org/10.1525/maq.1997.11.2.147.

Quisumbing, A. R., Meinzen-Dick, R., Raney, T. L., Coppenstedt, A., Behrman, J. A., \& Peterman, A. (2014). Closing the knowledge gap on gender in agriculture. In A. R. Quisumbing, R. Meinzen-Dick, T. L. Raney, A. Coppenstedt, J. A. Behrman, \& A. Peterman (Eds.), Gender and agriculture: Closing the knowledge gap (pp. 3-27). Dordrecht, The Netherlands: Food and Agriculture Organization of the United Nations and Springer Science+Business Media B.V.

Rogers, E. M. (2003). Diffusions of innovations (5th ed.). New York: Free Press.

Rubin, D., Ferdousi, S., Parvin, A., Rahman, S. M. T., Rahman, S., \& Redoy, M. (2018). Qualitative research on women's empowerment and participation in agricultural value chains in Bangladesh. Bangladesh and Washington, DC: International Food Policy Research Institute (IFPRI).

Schmidt, H., Pandit, B. H., Cornelissen, G., \& Kammann, C. I. (2017). Biochar-Based fertilization with liquid nutrient enrichment: 21 field trials covering 13 crop species in Nepal. Land Degrad. Develop., 28, 2324-2342. https://doi.org/10.1002/ldr.2761.

Siegel, K. R., Ali, M. K., Srinivasiah, A., Nugent, R. A., \& Narayan, K. M. V. (2014). Do we produce enough fruits and vegetables to meet global health need? PLOS ONE. https://doi.org/10.1371/journ al.pone.-0104059.

SPRING (2017). Bangladesh: Spillover effect of farmer nutrition schools among non-project beneficiaries. Arlington, VA, USA: Strengthening partnerships, results, and innovations in nutrition globally (SPRING), JSI Research \& Training Institute, Inc.

Statacorp. (2017). Stata statistical software: Release 15. College Station, Texas: Statacorp LLC.

Steiner, C., Teixeira, W. G., Lehmann, J., Nehls, T., Vasconcelos de Macêdo, J. L., Blum, W. E. H., et al. (2007). Long term effects of manure, charcoal and mineral fertilization on crop production and fertility on a highly weathered Central Amazonian Upland soil. Plant and Soil, 291, 275-290. https://doi. org/10.1007/s11104-007-9193-9. 
Temple, L., Biènabe, E., Barret, D., \& Saint-Martin, G. (2016). Methods for assessing the impact of research on innovation and development in the agriculture and food sectors. African Journal of Science, Technology, Innovation and Development, 8(5-6), 399-410. https://doi.org/10.1080/20421338.2016.12194 84.

Wendt, A. S., Sparling, T. M., Waid, J. L., Mueller, A. A., \& Gabrysch, S. (2019). Food and agricultural approaches to reducing malnutrition (FAARM): Protocol for a cluster-randomised controlled trial to evaluate the impact of a Homestead Food Production programme on undernutrition in rural Bangladesh. British Medical Journal Open, 9(7), e031037. https://doi.org/10.1136/bmjopen-2019-031037.

Wigboldus, S., Klerkx, L., Leeuwis, C., Schut, M., Muilermann, S., \& Jochemsen, H. (2016). Systemic perspectives on scaling agricultural innovations. A review. Agronomy for Sustainable Development, 36, 46. https://doi.org/10.1007/s13593-016-0380-z.

World Bank (2013). Bangladesh. Poverty assessment: Assessing a decade of progress in reducing poverty, 2000-2010. Bangladesh Development Series. Paper 31. Dhaka, Bangladesh and Washington, DC, USA: World Bank.

Publisher's Note Springer Nature remains neutral with regard to jurisdictional claims in published maps and institutional affiliations.

\section{Authors and Affiliations}

\section{Ipsita Sutradhar ${ }^{1}$ (D) . Meredith Jackson-deGraffenried ${ }^{2}$ (D) . Sayema Akter ${ }^{1}$ (D) Shannon A. McMahon ${ }^{3,4}$ (D) Jillian L. Waid ${ }^{2,3,7}$ (D) . Hans-Peter Schmidt ${ }^{5}$ (D) Amanda S. Wendt ${ }^{3,7}$. Sabine Gabrysch ${ }^{3,6,7,8}$ (D)}

1 BRAC James P Grant School of Public Health (BRAC JPGSPH), BRAC University, 68 Shahid Tajuddin Ahmed Sharani, Mohakhali, Dhaka 1212, Bangladesh

2 Helen Keller International-Bangladesh Country Office, House 10E, Road 82, Gulshan 2, Dhaka 1212, Bangladesh

3 Heidelberg Institute of Global Health, Heidelberg University, Im Neuenheimer Feld 324, 69120 Heidelberg, Germany

4 Social and Behavioral Interventions Program, Department of International Health, Johns Hopkins Bloomberg School of Public Health, Johns Hopkins University, 615 North Wolfe Street, Baltimore, MD 21205, USA

5 Ithaka Institute for Carbon Strategies, Ancienne Eglise 9, 1974 Arbaz, Switzerland

6 Heidelberg Center for the Environment, Heidelberg University, Im Neuenheimer Feld 229, 69120 Heidelberg, Germany

7 Research Department 2, Potsdam Institute for Climate Impact Research (PIK), Member of the Leibniz Association, PO Box 601203, 14412 Potsdam, Germany

8 Institute of Public Health, Charité - Universitätsmedizin Berlin, Charitéplatz 1, 10117 Berlin, Germany 